\title{
Desenvolvimento de animação para a odontologia como ferramenta no processo educacional
}

\author{
Development of animation for dentistry as a tool in education process
}

Adailton de Sousa Oliveira Junior
Uallace da Silva Oliveira*
Maria Luiza Anselmo ${ }^{* *}$
Alex Ferreira dos Santos
Sérgio Donha Yarid
Ismar Eduardo Martins Filho

\section{Resumo}

Introdução: a educação não precisa limitar-se ao discurso de um professor em sala de aula. Existem formas de tornar o aprendizado mais fácil e eficaz, e umas das principais formas é a linguagem audiovisual. Por seu intermédio, a informação ganha um formato mais simples de ser digerida e lembrada. Uma vertente importante da linguagem audiovisual é a animação, que tem um apelo forte especialmente ao público infantil. Pode-se aproveitar essa empatia que a animação exerce sobre as crianças para capturar a tão volúvel atenção delas. Objetivos: o objetivo deste trabalho é expor o valor da animação como forma de simplificar o aprendizado e apresentar uma animação desenvolvida pelo Núcleo de Extensão e Pesquisa Odontológica (Nepo), em parceria com o Centro de Pesquisa e Desenvolvimento de Software (CPDS), com intuito de mostrar a importância da escovação diária. Materiais e método: foram analisadas, na pesquisa, obras disponíveis na Biblioteca Jorge Amado, localizada no Campus de Jequié da Universidade Estadual do Sudoeste da Bahia, nas bases de dados do Scielo e do Google Acadêmico, nas bibliotecas virtuais da USP e da Unicamp. Para o desenvolvimento da animação foram utilizados softwares específicos da área de informática voltados para animação de imagens. Resultados: Na pesquisa foram abordados vários documentos relacionados ao uso da animação ou de materiais audiovisuais na educação em geral. Com base nesses estudos, criamos um vídeo -animado, mostrando a importância da animação no cotidiano das pessoas. Conclusão: a pesquisa mostrou a importância de encontrar formas diferentes de realizar o ensino.

Palavras-chave: Animação. Mídia. Audiovisual. Educação.

\section{Introdução}

A educação não precisa limitar-se ao discurso de um professor em sala de aula. Existem formas de tornar o aprendizado mais fácil e eficaz, entre essas o uso da linguagem audiovisual. Por meio dessa linguagem, a informação ganha um formato mais simples de ser interpretada e lembrada ${ }^{1-3}$.

Uma vertente importante da linguagem em estudo é a animação, a qual tem um apelo especialmente forte com o público infantil, que se encanta com as cores vivas e o ritmo dinâmico dos desenhos. Pode-se aproveitar essa empatia que a animação tem com as crianças para capturar a sua atenção, 
em geral tão volúvel, o que se torna ainda melhor se for usada uma linguagem mais próxima desse público.

A animação também é capaz de atrair os adultos, ainda que não sejam tão seduzidos quanto as crianças. Os antigos preconceitos, que categorizam o desenho como algo estritamente infantil, estão, aos poucos, sendo derrubados - nos cinemas, filmes animados costumam render bilheterias incríveis ${ }^{4-6}$ - e são vistos pelos mais diversos tipos de público.

A favor da animação encontram-se algumas características como, por exemplo, a imaginação. Diferente de uma produção visual em live-action, em que você precisa de atores, objetos de cena e outros requisitos, na animação, é muito mais fácil expressar qualquer ideia, por mais surreal que seja. Logo, basta saber desenhá-la e dar vida, em um papel ou no computador. Isso dá ao autor muito mais liberdade criativa, o que é um elemento precioso quando se quer encontrar a forma mais eficiente de passar uma mensagem.

Nesta discussão, serão observados outros fatores a respeito da animação e da produção audiovisual em geral no contexto do ensino.

\section{Materiais e método}

Para a pesquisa desenvolvida, foram analisadas obras disponíveis na Biblioteca Jorge Amado, localizada no Campus de Jequié da Universidade Estadual do Sudoeste da Bahia, nas bases de dados do Scielo e do Google Acadêmico, nas bibliotecas virtuais da USP e da Unicamp. Para o desenvolvimento da animação foram utilizados softwares específicos da área de informática voltados para animação de imagens que foi desenvolvida pelos estudantes e professores da Universidade Estadual do Sudoeste da Bahia (UESB). Para conseguir finalizar a animação, foram necessários 18 meses, período em que se realizou a definição do enredo, das personagens e a criação das cenas.

\section{Resultados}

A pesquisa apontou para diversos artigos, dissertações e teses relacionadas ao uso da animação ou do audiovisual na educação em geral, mostrando a importância da utilização dessas ferramentas para o melhor entendimento do conhecimento. Logo, fizemos uma animação para mostrar a importância da escovação diária. A seguir, será apresentado o enredo da animação desenvolvida.

\section{Enredo:}

$O$ ímico é um curta-metragem animado, que faz um alerta sobre os perigos do descuido com a higiene bucal. O protagonista é um mímico que, ao ser ridicularizado por sua falta de dentes, começa a se lembrar de momentos de sua vida os quais foram causa ou consequência desse problema. São retratadas situações como o consumo exagerado de doces e o fato de que uma dentição comprometida pode ser obstáculo na procura por um emprego. A mensagem final argumenta em favor de que esse problema pode ser evitado de forma muito simples, a saber: com a escovação diária. A seguir, será apresentada a descrição das etapas do enredo. A Figura 1 ilustra a animação desenvolvida pelo grupo de pesquisa da Universidade Estadual do Sudoeste da Bahia (UESB).
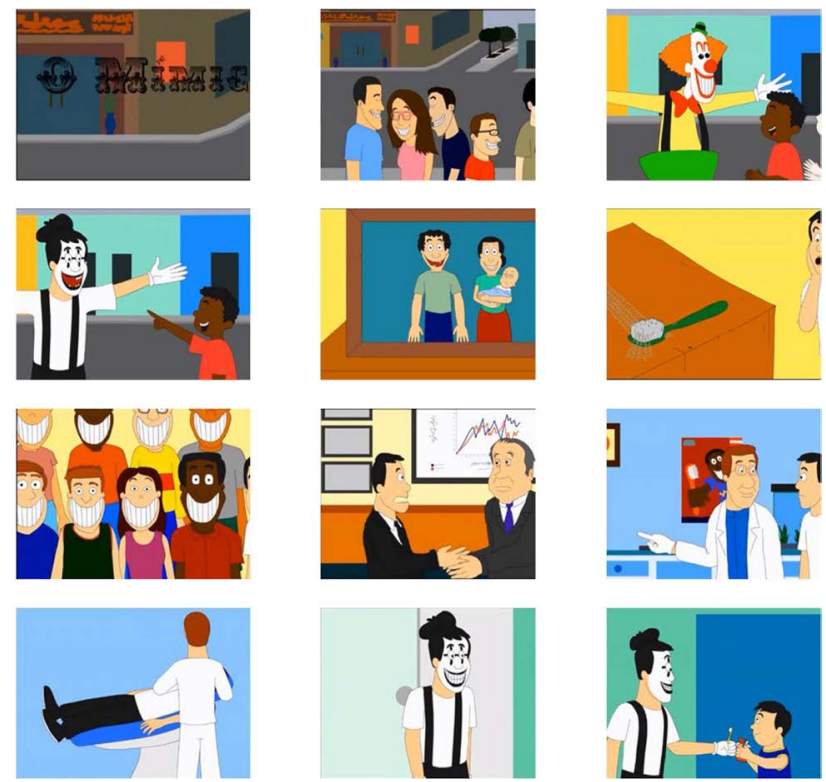

Fonte: disponível em: <http://www.youtube.com/watch?v=LTPPrmHPAmE.>.

Figura 1 - Cenas da animação desenvolvida

O vídeo retrata a história de um mímico, que tem problemas bucais e não consegue fazer as pessoas sorrirem. Ao andar pelas ruas, observa os sorrisos das pessoas que passam em sua frente. Um palhaço que está na rua faz brincadeiras, desperta alegria e risos entre as crianças. No entanto, o mesmo não ocorre com o mímico, para o qual as crianças sorriem por seu problema bucal e não por suas mímicas.

Logo, o mímico lembra-se de quando era pequeno e da figura de seu pai que não o incentivava a escovar os dentes, tinha problemas bucais e sempre comprava doces e salgados, cuja influência não o levou a não dar importância à escovação, apesar do incentivo da mãe.

Ao recordar-se de uma foto tirada da turma do ensino médio, percebe-se que, dentre todos os alunos, o único que não está sorrindo é ele, devido à falta de dentes em sua boca. Também, lembra-se das entrevistas de empregos em que não obteve sucesso devido a esse mesmo problema, ocasionando perda na sua autoestima. Então, para resolver o problema foi a um cirurgião dentista e, ao final do tratamento, conseguiu resgatar sua autoestima, sorrindo para todos, incentivando a escovação bucal. 


\section{Discussão}

Como observado por Santos ${ }^{7}$ (2010), o discurso linear em sala de aula não é a melhor forma de conquistar a atenção do aluno - especialmente nos dias de hoje -, em que o jovem está sempre recebendo muitas informações de forma cada vez mais dinâmica. A utilização do audiovisual pode realizar uma expressão melhor do conteúdo a ser passado, por ser uma linguagem com a qual os alunos sentem-se mais confortáveis ${ }^{8}$.

A oralidade, a escrita e a imagem são as três grandes etapas da comunicação humana, como afirma $\mathrm{Azzi}^{9}$ (1996), estando interligadas, especialmente na linguagem audiovisual. A mídia audiovisual possibilita o envolvimento de quem a assiste, sem que o espectador necessite recriar uma realidade imaginada ${ }^{10}$. Para $\operatorname{Rosa}^{11}$ (2000), o forte apelo emocional contido em um filme ou em um programa multimídia motiva a aprendizagem do conteúdo passado pelo professor.

Por volta da década de 1920, quando começou a haver um interesse em métodos mais eficazes de ensino, os meios de comunicação tornaram-se aliados da educação. Atualmente, os recursos audiovisuais estão cada vez mais presentes nas escolas, que, muitas vezes, contam com televisões e aparelhos de vídeo para poder estimular a criatividade do professor e do aluno.

Entretanto, como aponta Mogadouro ${ }^{12}$ (2011), o audiovisual é, ainda, na maioria das vezes, usado apenas como ilustração de um conteúdo, por sofrer um estigma de "texto não confiável". Muitos educadores ainda não dão o devido valor à comunicação que ultrapasse os meios tradicionais. $\mathrm{O}$ audiovisual faz parte do cotidiano do aluno, sendo visto em todos os momentos, mas na escola ele é considerado um coadjuvante.

Marcellino ${ }^{13}$ (1997) lembra que o conteúdo e a forma estão vitalmente conectados. $\mathrm{O}$ interesse em aprender é gerado pela forma e é isso o que vai garantir o êxito da aquisição de conhecimentos. Centrar a pedagogia em único ponto, seja esse o professor, o aluno ou o conteúdo, enfraquece todo o processo.

No entanto, é importante que o aluno tenha uma participação ativa quando assistir ao conteúdo, já que a interação é essencial para o aprendizado. Assim como aprendemos a ler, também precisamos aprender a observar. Rizzo Junior ${ }^{14}$ (2011) chama a atenção para o fato de que, frequentemente, o público relaciona-se, de forma passiva, com a produção audiovisual. $\mathrm{O}$ aluno que se limita a absorver calado tudo o que vê na tela não desenvolve o senso crítico. A escola é o lugar ideal para despertar esse poder. Souza ${ }^{15}$ lembra que a comunicação não é possível se não houver um código em comum e, muitas vezes, $o$ aluno não compreende um conteúdo por não estar familiarizado com a forma como esse étransmitido.

$\operatorname{Santos}^{7}$ (2010) reforça esse pensamento, informando que a exibição de material audiovisual em sala de aula é geralmente associada à diversão, pois é fundamental que o espectador tenha um olhar diferenciado sobre o que está sendo exibido. É necessário realizar debates após o filme e leituras adicionais sobre o tema, para estimular o interesse dos alunos pelo tema abordado e até mesmo chegar a novas informações ${ }^{16}$.

Pensando especificamente no aprendizado da criança, é preciso fazer com que o meio de ensino tenha um vínculo com o universo com o qual a criança está acostumada. Como observou Marcellino ${ }^{13}$ (1997), se a escola não puder ser enxergada como uma continuidade às experiências anteriores da criança, o conhecimento experenciado ali não fará sentido para ela. $\mathrm{E}$ a linguagem lúdica da animação pode se conectar muito bem ao universo infantil.

Há algumas características específicas das produções animadas, as quais as tronam ferramentas úteis no aprendizado. Silva ${ }^{17}$ (2001) observa que estruturas mentais relacionadas à criatividade, às emoções e às sensações são ativadas por elementos visuais e sonoros do desenho. Bento ${ }^{18}$ lembra que se tem contato com obras animadas desde a mais tenra infância e, portanto, há certa apropriação de ideologias e ensinamentos veiculados por essas.

Silva ${ }^{17}$ (2001) diz ainda que, no caso da criança, especificamente, a animação, muitas vezes, representa um primeiro contato com o mundo imagético que a estimula a trabalhar os próprios sentimentos, mesmo que inconscientemente. O que é visto na tela, combina-se a sensações interiores da criança e pode desencadear um processo de aprendizagem.

Ainda que a finalidade principal da animação seja o entretenimento, a experimentação desse gênero serve para a emancipação do imaginário, para possibilitar o sonho, para o exercício criativo e para a experiência de se emocionar por meio dos elementos visuais e sonoros ${ }^{19}$.

$\mathrm{O}$ desenho animado tem facilidade para se fixar em nosso imaginário, sendo outro fator que fortalece o seu vínculo com o ensino. As equipes envolvidas nesse tipo de produção costumam "gastar" um bom tempo pensando no design de personagem e no visual da animação como um todo, porque sabem que isso é essencial para que a história apresentada tenha um apelo persuasivo para o público.

Morais $^{20}$ (2011) chama a atenção para as informações visuais que podem estar contidas nos cenários e nas personagens de uma obra audiovisual. $\mathrm{Na}$ animação é mais fácil manipular esses elementos, fazendo com que a mensagem que o educador quer passar possa ir além da linguagem verbal.

Segundo Silva ${ }^{17}$ (2001), desenvolver um trabalho com imagens, com a linguagem dos cartoons, é estar em constante busca interativa com a sociedade em que vivemos. É ter consciência de que a comunicação não se esgota no verbal, e que a cada dia temos os nossos sentidos estimulados para captar novos códigos e novas mensagens. 


\section{Conclusão}

A pesquisa mostrou a relevância de encontrar formas diferentes de realizar o ensino. Centrar a exposição do conhecimento nos meios tradicionais tem pouca eficácia, ainda mais quando se fala para uma geração acostumada com uma linguagem bem mais dinâmica.

A animação pode ser uma arma poderosa para o ensino, pois faz parte do cotidiano das pessoas, o que pode facilitar a absorção de novos conhecimentos, e é uma das principais fontes de entretenimento da criança. Seus elementos visuais e sonoros estimulam estruturas mentais.

A utilidade da animação também tem a ver com sua facilidade para se conectar a experiências anteriores do espectador. Isso pode ser aproveitado de uma melhor forma se for estimulado, no ambiente escolar, o desenvolvimento de um senso crítico na pessoa, a fim de evitar que as informações sejam absorvidas passivamente.

A animação desenvolvida teve o intuito de mostrar a importância da escovação diária e, como supracitado, tem maior impacto no aprendizado da criança do que já referenciado na explicação dos profissionais de saúde, dos familiares e dos professores.

\section{Abstract}

Introduction: education does not need to be limited to a professor's speech in a classroom. There are ways to make learning easier and more effective, and one of the main of these ways is audiovisual language, through which information receives a format that is simpler to digest and remember. An important aspect of audiovisual is animation, which has an especially strong appeal with child audiences. It is possible to take advantage of this empathy that animation has with children to capture their fickle attention. Objectives: to show the value of animation as a way to simplify learning and present an animation developed by the Nucleus of Extension and Research in Dentistry (NEPO) in partnership with the Center of Software Research and Development (CPDS) in order to show the importance of daily brushing. Materials and method: for the research, analyses were performed of works available in the Jorge Amado Library, located in the Jequie campus of the State University of Southwest of Bahia, in Scielo and Google Scholar databases, and in virtual libraries of USP and Unicamp. Informatics-specific Software focused on images animation were used for the development of the animation. Results: the research led us to several documents related to the use of either animation or general audiovisual on education. Based on these studies, we created an animated film showing the importance of animation in people's everyday life. Conclusion: the research showed the importance of finding different ways of teaching.

Keywords: Animation. Audiovisual. Education.

\section{Referências}

1. Camargo LB, Alencar CJF, Chao LW, Raggio DP, Haddad AE. Desenvolvimento de material didático dinâmico em odontopediatria para utilização na teleodontologia: utilização do software Macromedia. Rev Paul Odontologia 2009; 31:31-35.

2. Haddad AE. A Odontologia na política de formação dos profissionais de saúde, o papel da teleodontologia como ferramenta do processo de ensino-aprendizagem e a criação do Núcleo de Teleodontologia da FOUSP. [Tese de Livre Docência]. São Paulo: Faculdade de Odontologia da USP; 2011.

3. Alencar CJF. Impacto das novas tecnologias de informação e comunicação, através do blended learning, aplicadas aos graduandos em Odontopediatria. [Tese de Doutorado]. São Paulo: Faculdade de Odontologia da USP; 2012.

4. Barbosa D. Madagascar 3 lidera bilheterias nos Estados Unidos". [Citado2014 mar 16]. Disponível em URL: <http:// exame.abril.com.br/negocios/empresas/noticias/madagascar-3-lidera-bilheterias-nos-estados-unidos $>$.

5. Oliveira AJ. Rio é campeão nas bilheterias do Brasil e do mundo. [Citado 2014 mar 16]. Disponível em: <URL: http:// www.animatoons.com.br/rio/rio-e-campeao-nas-bilheterias-do-brasil-e-do-mundo>.

6. Subers, R. Toy Story 3 Reaches $\$ 1$ Billion. [Citado 16 mar 2014]. Disponível em: <http://boxofficemojo.com/ news/?id=2904>.

7. Santos PC. A utilização de recursos audiovisuais no ensino de ciências: tendências entre 1997 e 2007. [Dissertação de Mestrado]. São Paulo: Faculdade de Educação da USP; 2010.

8. Miranda CEA. O que estamos vendo?: um estudo sobre imagem e educação na era de reprodutividade técnica. [Dissertação de Mestrado].Campinas: Programa de Pós-Graduação em Educação; 1996.

9. Azzi R. Cinema e educação: orientação pedagógica e cultural de vídeos I. São Paulo: Paulinas; 1996.

10. Magarão JFL, Struchiner M, Giannella T. Potencialidades pedagógicas dos audiovisuais para o ensino de ciências: uma análise dos recursos disponíveis no portal do professor. III Encontro Nacional de Ensino de Ciências da Saúde e do Ambiente, Niterói, Brasil; 2012.

11. Rosa PRS. O uso dos recursos audiovisuais e o ensino de ciências. Caderno Brasileiro de Ensino de Física. UFSC, Florianópolis, SC, Brasil; 2000.

12. Mogadouro CA. Educomunicação e escola: o cinema como mediação possível (desafios, práticas e proposta). [Tese de Doutorado]. São Paulo: Escola de Comunicações e Artes da USP; 2011.

13. Marcellino NC. Pedagogia da animação. São Paulo: Papirus; 1997.

14. Rizzo Junior SA. Educação audiovisual: uma proposta para a formação de professores de ensino fundamental e de ensino médio no Brasil. [Tese de Doutorado]. São Paulo: Escola de Comunicações e Artes da USP; 2011.

15. Souza KI. Vídeo digital na educação: aplicação da narrativa audiovisual. [Tese de Doutorado]. Campinas: Faculdade de Educação da Unicamp; 2009.

16. Champangnatte DMO, Nunes LC. A inserção das mídias audiovisuais no contexto escolar. Educação em Revista. [periódico on-line]. 2011, v. 27, n.3, p. 15-38.

17. Silva STA. Desenho animado e educação. In: CHIAPPINI, Ligia (Coord.). Outras linguagens na escola: publicidade, cinema e TV, rádio, jogos, informática. São Paulo: Cortez, 2001. p.109-29. 
18. Bento F, Neves FM. Turma da Mônica: o que permeia a relação entre cinema de animação e educação? [Citado 2014 mar 16]. Disponível em URL: < http://www.ppe.uem.br/publicacoes/seminario_ppe_2009_2010/pdf/2009/06.pdf.

19. Gomes MP, Machado MTC, Manhães ACTS, Santos TS, Soares RAR. Desenho animado: recurso pedagógico no processo ensino-aprendizagem de educação ambiental. Ensino, Saúde e Ambiente 2012;5 (2), 90-101, ago.

20. Morais WR, Garíglio MI, Aguiar CG. A linguagem audiovisual nos desenhos animados infantis: o caso do Peixonauta. Anais do XV Congresso Nacional de Linguística e Filologia. Rio de Janeiro: 2011.

\section{Endereço para correspondência:}

Alex Ferreira dos Santos

Universidade Federal do Recôncavo da Bahia (UFRB)

Centro de Ciência e Tecnologia em Energia e

Sustentabilidade (Cetens)

Avenida Centenário, 697, Bairro SIM

44085-132 Feira de Santana-BA

E-mail: alex.ferreira@ufrb.edu.br

Recebido: 16/03/2014. Aceito: 03/12/2014. 